\title{
Mitigation activities to reduce emission of agricultural greenhouse gases in Hungary
}

\author{
János Lazányi \\ University of Debrecen Faculty of Applied Economics and Rural Development \\ H-4032 Debrecen, Böszörményi út 138. Hungary
}

\begin{abstract}
Summary: Pressure on natural resources and the global environment have been identified as the most important challenges to maintain prosperity and improve environmental care. Agriculture is responsible for only a small proportion of carbon dioxide $\left(\mathrm{CO}_{2}\right)$ emissions, but the sector is more closely associated with emissions of other greenhouse gases such as methane $\left(\mathrm{CH}_{4}\right)$ and nitrous oxide $\left(\mathrm{N}_{2} \mathrm{O}\right)$. The global warming potential of agricultural activities defined as greenhouse gas (GHG) emissions in $\mathrm{CO}_{2}$ equivalents is relatively low in Hungary, when calculated per land area. However this difference decline, when a GHG emission is calculated per product unit, as yields are lower then in West European countries. Environmental load caused by agriculture is also low in Hungary, where increasing part of EU resources are used for the long-term preservation of natural resources and for the raising of awareness of sustainable farming. The strength of the environmental situation of Hungary, consist of several elements, such as the rich bio-diversity, the significant size of territories falling under natural protection, the extent and importance of forests and the low environmental load from crop production. Among the weaknesses the nitrate load of the animal husbandry farms, the increasing water and wind erosion, the soil compaction and degradation have to be taken into consideration. Climate change has high risk potential and the mitigation activities of the New Hungary Rural Development Programme (HRDP) are investigated in this paper with the aim to increase mitigation activities in rural area and reduce the causes of climate change.
\end{abstract}

Key words: Climate change, Rural Development Programme, Mitigation, Hungary

\section{Introduction}

The biosphere is a strong determinant of the chemical composition of the atmosphere. A wide range of carbon, nitrogen, and sulphur gases have been emitted and absorbed by the biosphere. There are also evidences that the expanding human use and alteration of the biosphere for food, fuel and fibre production are contributing to increasing atmospheric concentrations of GHG gases. The dominant gas in this category is carbon dioxide $\left(\mathrm{CO}_{2}\right)$. Other important $\mathrm{GHG}$ gases include methane $\left(\mathrm{CH}_{4}\right)$ and nitrous oxide $\left(\mathrm{N}_{2} \mathrm{O}\right)$. Indirect GHGs, including carbon monoxide (CO), oxides of nitrogen $\left(\mathrm{NO}_{\mathrm{x}}\right)$, and volatile organic compounds are also produced from land-use change and forest management activities, where burning is involved.

The global warming potential of organic and integrated farming systems is considerably smaller than that of conventional. Recent analyses have suggested that growth of existing forests in temperate regions may be a significant carbon sink potentially as much as $0.7 \mathrm{Pg} \mathrm{C}$ annually. Estimates of $\mathrm{CO}_{2}$ emissions due to land-use change vary considerably according to the fate of the land cleared, the amounts of biomass contained in different ecosystems and the amount of carbon released, when soils are disturbed.

Agriculture is the largest user of rural land, and a key determinant of the quality of the countryside and the rural environment. The importance and relevance of rural development have increased with the recent enlargement of the European Union and contributes to sustainable development. The new agricultural model reflects the role of multifunctional farming, diversity of landscapes, cultural and natural heritage. The guiding principles for the CAP are set out by the European Council of Goteborg, which concluded, that economic performance of agriculture must go hand in hand with the sustainable use of natural resources. CAP minimizes waste production, maintains biodiversity, preserves ecosystems and avoids desertification. CAP encourages healthy, high-quality products, environmentally sustainable production methods including organic production and the protection of biodiversity.

The new rural development policy can make a key contribution to competitiveness and sustainable development in the coming years. Agriculture and forestry represent more than $90 \%$ of land use in Hungary and the environmental performances of them are closely connected to preservation and enhancement of natural resources. As regards water quality, total nitrogen surplus has declined since 1990, although some regions still experience some nutrient leaching. Problems of soil degradation persist in many areas of Hungary, although, an increasing share of agricultural area is devoted to organic production and integrated farming. With the implementation of about 2 million hectares of Natura 2000 territory, there are significant advances in the protection of biodiversity. The former value of the protected 
areas in Hungary was about 0.75 million hectares, $90 \%$ of it remains in Natura 2000, and further 1.2 million hectares have been added. The present value reaches 1.92 million hectares, $21 \%$ of the total territory of Hungary.

Long-term trends in forestry also shape climate change mitigation in Hungary as forested area in 1922 was as low as $8 \%$. Now, forestry occupies more than $18 \%$ of the country and becoming increasingly important in water management and in the fight against erosion and the harmful consequences of climatic change. The size of forestry in nature conservation areas is considerable and additional areas have already been designated as parts of the Natura 2000 network. In this way, rural areas face particular challenges as regards growth, jobs and sustainability. The agricultural and food sectors, on the other hand, profit the opportunities offered by new approaches, technologies and innovation to meet market demand both in Europe and globally. Investment in human capital will allow rural areas to look to the future with confidence.

\section{Material and methods}

Agriculture and forestry sector is unique in having the ability to produce and to sequester greenhouse gases, as well as to provide biomass-derived renewable energy. In this paper climate change mitigation is considered on the bases of the New Hungary Rural Development Programme. Mitigation activities to reduce agricultural greenhouse gases emissions are focused on the following subjects:

- $\mathrm{CH}_{4}$ emissions from enteric fermentation in domestic livestock: Methane is produced as a byproduct of enteric fermentation, a digestive process by which carbohydrates are broken down by microorganisms into simple molecules. Both ruminant and some non-ruminant animals produce methane, but ruminants are the most important source since they are able to digest cellulose, due to the presence of specific micro-organisms in their digestive tracts. The amount of $\mathrm{CH}_{4}$ released depends on the type, age and weight of the animal, the quality and quantity of the feed and the energy expenditure of the animal.

- $\mathrm{CH}_{4}$ emissions from manure management: $\mathrm{CH}_{4}$ is produced from the decomposition of manure under anaerobic conditions. These conditions often occur where large numbers of animals are managed (dairy farms, beef feedlots, swine and poultry farms), and manure is stored in large piles or disposed of in lagoons.

- $\quad \mathbf{N}_{2} \mathrm{O}$ emissions from manure management: During storage of manure, some manure nitrogen is converted to $\mathrm{N}_{2} \mathrm{O}$. Emissions of $\mathrm{N}_{2} \mathrm{O}$ related to manure handling are included in this source category. Manure-related $\mathrm{N}_{2} \mathrm{O}$ emissions from soils are considered as agricultural soil emissions.

- $\mathbf{C H}_{4}$ emissions from rice cultivation: Anaerobic decomposition of organic material in flooded rice fields produces methane. The amount $\mathrm{CH}_{4}$ emitted is a function of soil type, temperature, irrigation practices and fertiliser use. The integrated $\mathrm{CH}_{4}$ flux depends upon the input of organic carbon, water regimes, soil type, time and duration of drainage.

- $\mathrm{CH}_{4}, \mathrm{CO}, \mathrm{N}_{2} \mathrm{O}$, and $\mathrm{NO}_{\mathrm{X}}$ emissions from the burning of agricultural residues: The burning of crop residues is a significant source of emissions of methane, carbon monoxide, nitrous oxide, and nitrogen oxides. Since 1995, burning of agricultural residues is banned in Hungary

- $\mathrm{CH}_{4}, \mathrm{CO}_{2}$, and $\mathrm{N}_{2} \mathrm{O}$ emissions from agricultural soils: Emissions of $\mathrm{N}_{2} \mathrm{O}$ from agricultural soils are primarily due to the microbial processes of denitrification. Direct soil emissions may result from the following nitrogen input to soils: (1) synthetic fertilisers, (2) nitrogen from animal waste, (3) biological nitrogen fixation, (4) reutilised nitrogen from crop residues, and (5) sewage sludge application. Soil cultivations also increase soil organic matter mineralisation and $\mathrm{N}_{2} \mathrm{O}$ emissions. Increased amount of nitrogen added to the soil generally result in higher $\mathrm{N}_{2} \mathrm{O}$ emissions. Direct soil emissions of $\mathrm{N}_{2} \mathrm{O}$ from grazing animals and indirect $\mathrm{N}_{2} \mathrm{O}$ emissions take place after nitrogen is lost from the field as $\mathrm{NO}_{\mathrm{x}}, \mathrm{NH}_{3}$ and after leaching or runoff. Agricultural soils may also emit or remove $\mathrm{CO}_{2}$ and/or $\mathrm{CH}_{4}$ when peat compost is used as a soil amendment. Carbon dioxide emissions from limed soils are also important.

- $\mathrm{CO}_{2}$ and $\mathrm{N}_{2} \mathrm{O}$ emissions from land use change: Most important land-use changes that result in GHG emissions and removals are (i) changes in forest and other woody biomass stocks, (ii) forest and grassland conversion, (iii) abandonment of croplands, pastures, plantation forests, or other managed lands and (iv) changes in soil carbon.

\section{GREENHOUSE GASES EMISSION AND MITIGATION ACTIVITIES}

\section{1. / Strategic objectives of the New Hungary Rural Development Programme}

In line with the overall aim of sustainable development, HRDP seeks to change the management of farming so as to improve the connections between environmental, social and economic impacts of rural development. The main strategic objectives under which rural development activities will be supported during the period 2007-2013 are as follows:

\section{Axis 1: Improving the competitiveness of the agricultural and} forestry sector: Minimum of $10 \%$ of national rural development fund should be committed to Axis 1 including payments for young farmers, early retirement of farmers and farm workers, modernisation of agricultural holdings, improving the economic value of 
forests, supporting producer groups and promotion activities under food quality schemes.

Axis 2: Improving the environment and the countryside:

Minimum of $25 \%$ of national rural development fund should be committed to Axis 2 including agrienvironment payments, Natura 2000 payments, forest-environment payments, restoring forestry potential and introducing prevention actions, support for non-productive investments.

Axis 3: The quality of life in rural areas and diversification of the rural economy: Minimum of $10 \%$ of national rural development fund should be committed to Axis 3 payments including diversification into non-agricultural activities, encouragement of tourism and basic services for rural population, village renewal and development, training and skills acquisition measures.

Axis 4: Leader: The LEADER approach is used for the delivery of the other three axes through area based local development strategies, local public-private partnerships, implementation of innovative approaches, implementation of cooperation projects, networking of local partnerships.

\section{2./ Emissions of greenhouse gases}

Carbon dioxide is the main climate change gas, produced largely by combustion of fossil fuels (Figure 1 and 2). Emissions of carbon dioxide are from direct energy use, such as diesel in tractors, gas to heat and electricity in livestock buildings. Agriculture and forestry currently account for about $10-11 \%$ of total greenhouse gas emissions. Agriculture is responsible for a very small share of $\mathrm{CO}_{2}$ emissions and the sector can help to mitigate $\mathrm{CO}_{2}$ emissions from other sources through carbon sequestration in soils and timber by land use, land use change and forestry (LUCUF). Agricultural practices are more significant sources of other gasses, including methane, and nitrous oxide, which significantly contribute to climate change (Figure 2). In 2007 , energy sector accounted for just over $70 \%$ of $\mathrm{CO}_{2}$ emissions. Since 1985, emissions from energy, industrial processes and agriculture have fallen continually, while those from waste management have risen, as shown in Figure 3.

Emissions of methane and nitrous oxide from agriculture have declined substantially in the early 1990s, largely because of a reduction in livestock numbers and fertiliser use (Figure 4). In 2007, agriculture produced $33 \%$ of the total $\mathrm{CH}_{4}$ emissions. Emissions of methane fell by $48 \%$ between 1985 and 2007. About $86 \%$ of this methane comes from enteric fermentation and $14 \%$ from manure management. Nitrous oxide emissions also fell by 40 per cent between 1985 and 2007 and agriculture is the main source, accounting for about two thirds of $\mathrm{N}_{2} \mathrm{O}$ emissions. This originates mainly from agricultural soils. The nitrous oxide emissions arise from manures and artificial fertilisers. Methane and nitrous oxide have global warming potentials that are greater than carbon dioxide by 21 and 310 times respectively.

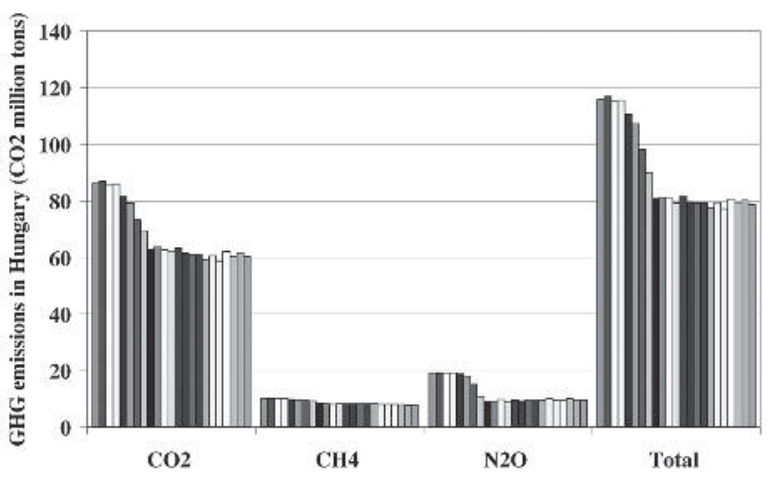

Figure 1: Emissions of different GHG in Hungary between 1985 and 2007 (million tons)

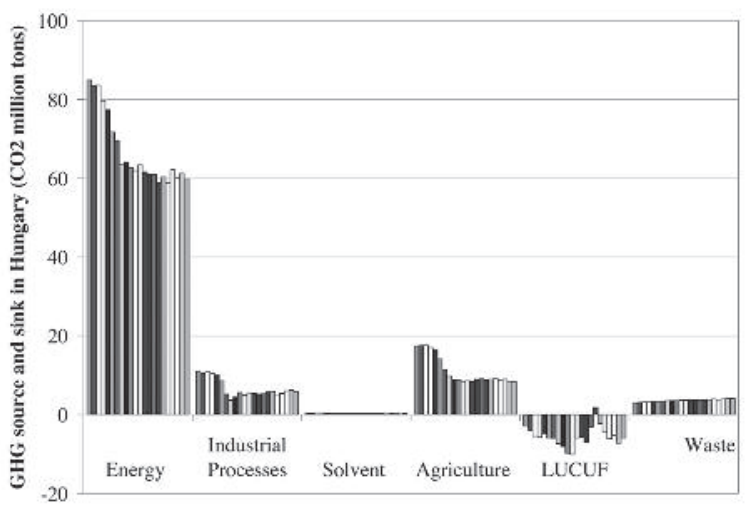

Figure 2: Greenhouse gas source and sink in Hungary between 1985 and 2007 by categories (million tons)

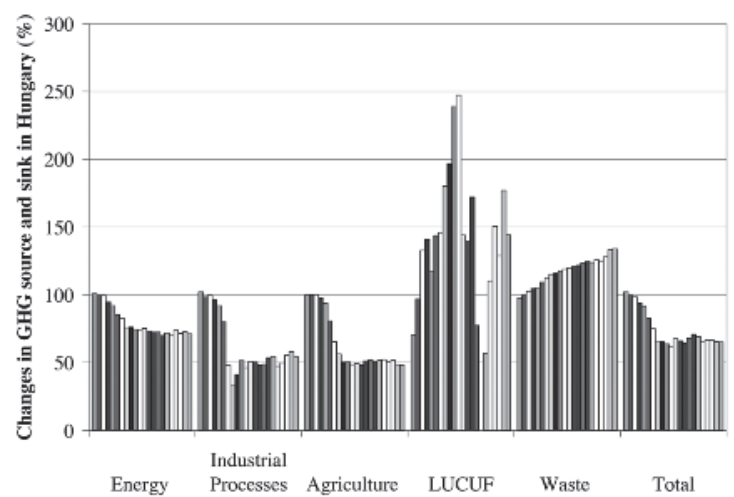

Figure 3: Changes in GHG source and sink in Hungary between 1985 and 2007 by categories (\%)

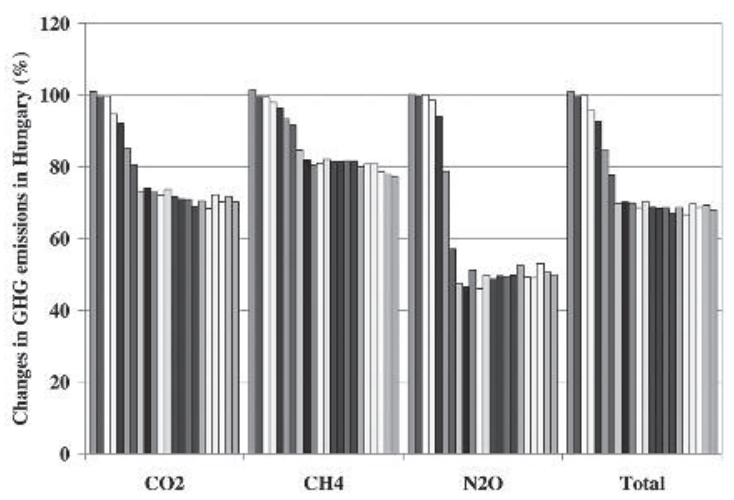

Figure 4: Changes in different GHG emissions in Hungary between 1985 and $2007(\%)$ 


\section{3. / Climate change mitigation in the New Hungary Rural Development Programme}

Specific attention is given for measures to improve manure storage and spreading techniques to reduce nitrate loss and $\mathrm{CH}_{4}$ emission. Efficient management of solid and liquid manure is essential for the reduction of methane emissions, originating from biological fermentation in livestock manure management. Manure management and septic pits are good examples of investments, similarly to equipment for precision farming and spreader for better application of mineral fertilisers and organic manure. One of the objectives of the HRDP based on National AgriEnvironmental Programme (NAEP) is to support the development of organic farming as an environmentallyfriendly method of production. The objective is to ensure adequate levels of technical and economic knowledge, skills in management and sustainable management of natural resources including the requirements of cross compliance, renewable energy sources and organic production. Climate change mitigation benefits are likely as the global warming potential of organic and integrated farming systems is considerably lower, than, that of conventional. HRDP also promotes the use of environmental planning in farm management practices, such as nutrient management and crop rotation planning. Soil and water protection scheme provides support for nutrient management, including storage and application of livestock manures.

HRDP supports the development of environmentallyfriendly production method with economic potential. In this respect, important objectives of the HRDP are to conserve soil and water resources, including those areas affected by erosion and risk of nutrient losses. Soil and water protection scheme provides support for the introduction of sustainable crop rotations, intercropping, green cover and legumes such as peas, beans, lupine, soybean, alfalfa and clover. Purchase and installation of new equipment also improves energy efficiency.

HRDP intends to restore traditional agricultural landscape features, which have cultural, scenic and environmental value. A corresponding activity is the maintenance of high natural value grasslands and livestock management. Measures involve the maintenance of a maximum density of livestock in order to assure a good ecological state for the meadows and pastures and to keep permanent grass cover. The extensive grassland scheme promotes grassland management based on animal husbandry. Extensive pastures management, diversification of grass species and reduced fertilisation help to increase soil organic levels and climate change mitigation objectives.

Conversion of agricultural land into forest and conversion of arable land to permanent pastures are connected to soil erosion control and has an effect on GHG mitigation. Ensuring adequate levels of technical and economic skills in management and business, new technologies, product quality and safety, sustainable management of natural resources, renewable energy use and organic production are the most important operational objectives. Development of new technologies and processes, forestation of non-agricultural land will also contribute to climate change mitigation and enhance biodiversity in Hungary.

To meet the particular requirements linked to the nitrate directive in livestock sector HRDP states that animal husbandry in Hungary lacks compliance with environmental protection requirements, and significant investments are needed in manure storage and management. Within the framework of HRDP, the storage and use of manure, including biogas production facilities are supported. Investments in equipment for better application of mineral fertilisers and manure are also detailed in the programme. Actions on energy-saving machinery involve strong emphasis on environmentally sound, cost-efficient and energy-saving equipment, but details are also important in respect of climate change mitigation.

Organic farming and grassland management schemes promote the adoption of environmental friendly management practices compliant with the rules and regulations of organic production in order to preserve grassland habitats of high natural value. HRDP includes the integrated crop production scheme, which involves sustainable nutrient management, integrated plant production, crop rotation and soil cultivation. Soil conservation techniques, such as reduced tillage, permanent green cover, catch crops, stubble management are also integrated in the HRDP in order to improve quality of soil, surface and ground waters. The integrated crop production scheme promotes rational nutrient management. The anti-erosion scheme applies various methods at arable lands, including conversion of low fertility arable lands into forestry or grassland. In areas threatened by floods, erosion and on land near vulnerable water resources, supports are granted for the first forestation. This is in line with management of greenhouse gases.

Organic matter plays an important role in maintaining soil fertility and structural stability. Soils are a major reservoir of carbon. The lost soil carbon is likely to increase $\mathrm{CO}_{2}$ concentration in the atmosphere, and exacerbating global warming. Loss of soil carbon also affects soil functioning, resulting in an increase of erosion and loss of soil biodiversity. Mitigation measures of HRDP encompass the control of carbon losses from soils. Protection against erosion is a well defined climate change mitigation objectives similarly to the use of water reservoirs and livestock protection on semi-natural and natural grasslands. Extensive pastures management and protection of biotopes of semi-natural and natural grasslands totally excludes mineral fertilizers and liquid manure from protected area. This applies to land situated in a vulnerable zone delimited with the Directive 91/676/EEC and in less favoured areas. These measures are also in line with climate change mitigation objectives.

Agriculture can also be used to produce renewable energy, both as biomass and bio-fuels. Sources of energy include both residues and crops grown for energy. While the carbon savings from using perennial energy crops are 
significant, net carbon savings from annual food crops such as cereals and oil crops, which can be used to produce transport fuels, are much lower and have different environmental impacts. To meet both energy and environmental objectives the location, landscape characteristics, water availability, the size and arrangement of planted fields have to be considered. Important aims of HRDP are to address climate change objectives with increasing emphasis on resource protection for the benefits of society.

The drivers for increased energy efficiency are mainly economic. The contribution of resource efficiency can make to climate change mitigation are recognised in the HRDP, as well as the benefits for soil, air and water quality. This suggests a need for public intervention in support of innovative technologies and resource management techniques. Anaerobic digestion (AD) is a renewable energy technology that has significant potential to contribute to climate change and wider environmental objectives. It helps reduce greenhouse gas emissions by capturing methane from the decomposition of organic materials, such as manure and slurry, food waste and sewage sludge. The biogas can then be used as a renewable energy source for heat, power or as a transport fuel. Public intervention is necessary to disseminate the technology and to help early adopters. Specialist advice and training help farmers adapt to the challenges of CAP reform and to the increasing emphasis on mitigating the effects of climate change.

Public intervention is necessary to disseminate results of R\&D activities. HRDP helps agriculture and forestry sector to play its full part in tackling climate change and exploring how environmental stewardship can contribute to achieving the climate change objectives. This includes promoting resource efficient farm management and developing a communicational strategy to raise awareness of climate change issues. Taking forward the non-food crops strategy to substitute fossil fuels with renewable products and measures under nitrates action plan, which also support climate change mitigation goals in Hungary. Trainings in agriculture and forestry include tasks related to renewable energy, such as production, utilization and primary processing of biomass for energetic purposes. Without this, the opportunity to bring the technology to market and achieve the public benefits might be lost. Support granted to farmers and forest holders to cover the utilization of professional advisory services, and increase awareness in the field of climate change mitigation to maintain good agricultural and environmental condition.

\section{Discussion}

The New Hungary Rural Development Programmes from 2007 to 2013 are based on recognition of the need for healthy functioning of the environment and economy. Many aspects of the environment, such as the quality of air and water are improving, but the challenge is to encourage production and consumption patterns to reduce environmental impacts. This creates opportunities for less resource use, pollution and waste throughout the entire food chain and consequently increases competitiveness of farming and food businesses. This can be achieved through raising awareness of the economic and environmental opportunities, applying resource efficient techniques, making use of innovative technology, access to advice on resource efficiency, helping farmers and land managers understand the increasing need to protect soil organic matter. To mitigate climate change, rural development requires strategic approach to competitiveness, job creation and improved governance in the coming years.

\section{References}

Annual Status Report of the Annual Inventory of Hungary 2009. United Nations Framework Convention on Climate Change (UNFCCC)

Council Regulation (EC) 1698/2005 on Support for Rural Development by the European Agricultural Fund for Rural Development

IPCC (Intergovernmental Panel on Climate Change, (2007): The physical science basis, Contribution of Working Group I to the Fourth Assessment Report of the Intergovernmental Panel on Climate Change, Cambridge University Press, Cambridge.

IPCC (Intergovernmental Panel on Climate Change), (2007) Climate change 2007: mitigation, Contribution of Working Group III to the Fourth Assessment Report of the Intergovernmental Panel on Climate Change, Cambridge University Press, Cambridge

New Hungary Rural Development Programme is the National Rural Development Programme prepared for the 2007-2013 period

Report of the Individual Review of the Greenhouse Gas Inventory of Hungary Submitted in 2006. United Nations Framework Convention on Climate Change (UNFCCC)

Report of the Individual Review of the Greenhouse gas Inventories of Hungary Submitted in 2007 and 2008. United Nations Framework Convention on Climate Change (UNFCCC)

WMO Statement on the Status of the Global Climate in 2008. World Meteorological Organization (WMO), Geneva, Switzerland. 
